\title{
Extraction of Soluble Sugars from Green Coffee Beans Using Hot Water and Quantification by a Chromatographic Method without an Organic Solvent
}

\author{
Leonel Vinicius Constantino ${ }^{1}$, Douglas Mariani Zeffa ${ }^{2 *}$, Alessandra Koltun ${ }^{2}$, Mariana Ragassi Urbano ${ }^{1}$, \\ Alisson Wilson Santos Sanzovo ${ }^{1}$ and Suzana Lucy Nixdorf ${ }^{1 *}$ \\ ${ }^{\prime}$ Universidade Estadual de Londrina (UEL), Rod. Celso Garcia Cid, Km 380, 86057-970, Londrina, PR, Brazil \\ 'Universidade Estadual de Maringá (UEM), Avenida Colombo, 5790, 87020-900, Maringá, PR, Brazil
}

Received: 06 Sep 2019; accepted: 07 Jan 2020

\begin{abstract}
An optimal condition for extraction of soluble sugars from green coffee using water and a validated chromatographic method for its separation and quantification were proposed in this research. An orbital incubator shaker (OIS) and microwave-assisted extraction (MAE) were the 2 techniques used to extract soluble sugars. In such experiments, the variables: sample amount $(300,400$, and $500 \mathrm{mg})$, time $(30,60$, and $90 \mathrm{~min})$, and temperature $\left(30,45\right.$, and $\left.60{ }^{\circ} \mathrm{C}\right)$ were tested. The separation of sugars was performed in a chromatographic system (highperformance liquid chromatography refractive index detector [HPLC-RID]), which presented the selectivity for the analytes, a limit of detection of $0.020 \mathrm{~g} / \mathrm{L}$, a limit of quantification of $0.0625 \mathrm{~g} / \mathrm{L}$, and recovery rates greater than $95 \%$. The repeatability and inter-day precision had low dispersion, RSD $<2.0 \%$ and $<3.0 \%$, respectively. Sucrose content ranged from 0.65 to $2.39 \mathrm{~g} / \mathrm{L}$ using an OIS and from 1.19 to $2.72 \mathrm{~g} / \mathrm{L}$ by MAE, while glucose and fructose concentration varied from 0.08 to $0.12 \mathrm{~g} / \mathrm{L}$ using both methods. The OIS technique is preferably indicated for extraction of soluble sugars at the following conditions: $500 \mathrm{mg}$ of grounded green coffee, $90 \mathrm{~min}$, and $60{ }^{\circ} \mathrm{C}$. The proposed method for soluble sugar extraction and quantification may be applied in research laboratories and food industries since it is a low-cost and environment-friendly technique.
\end{abstract}

Keywords: carbohydrates, HPLC-RID, orbital incubator shaker, microwave-assisted extraction

\section{Introduction}

Coffee is known worldwide for its appreciable beverage, and Brazil is one of the largest producers and exporters of green beans, with a total production of 3,019,051 tons and an average yield of $15,135 \mathrm{~kg} / \mathrm{ha}[1,2]$. The country even occupied the first position in the world's production rank from 2001 to 2015, when Brazil's share of coffee bean global exports was approximately $30 \%$ [3].

Among the coffee species, there is greater commercial interest for Coffea arabica L., since it confers better sensorial characteristics to the beverage, and it represents $70 \%$ of the world grain production [3-5]. Aside from the species, coffee quality depends on several factors related to the beans pre- and postharvest processes, which contribute to the characteristic flavor and aroma of the beverage [5, 7-9].

Carbohydrates are the main components of green, roasted, and soluble coffee, and they account for $50 \%$ of its dry matter, on average [9]. Moreover, coffee quality relies mainly on the soluble sugar concentration in its grains, such as sucrose, glucose, and fructose. These components indicate the physiological maturity of plants, and therefore, the most appropriate harvesting time [10-15].

From the early stages of grain development to its maturation, glucose and fructose are the main soluble sugars in coffee beans, in which glucose levels are twice the concentration of fructose [16]. At the beginning of the process, glucose concentration ranges from 8 to $12 \%$ of the grain dry matter and

\footnotetext{
*Author for correspondence. leonel@uel.br; s.nixdorf@hotmail.com.
}

decreases to $0.03 \%$ at the end of maturation. Unlike glucose, the concentration of sucrose increases during grain maturation, reaching about 5 to $12 \%$ of mature coffee bean dry matter $[14,17]$.

According to the Lane Enyon method cited by Association of Official Analytical Chemists (AOAC, 1990) [18], the use of $70 \%(v / v)$ ethanol with manual agitation is recommended for sugar extraction from food, since it is a solvent compatible with polar solutes, and it presents a $\mathrm{pH}$ that improves the extraction efficiency. Although this is the current recommendation, there are other viable alternatives for extracting green coffee components, such as the use of hot water, orbital incubator shaker (OIS), and microwave-assisted extraction (MAE) systems $[16,19,20]$. However, these alternative methods and specific techniques are under-researched.

Among the various techniques for sugar quantification, high-performance liquid chromatography (HPLC) stands out for its efficiency and precision. Due to appropriate combinations of the stationary phase and the detection system, it allows fast separation of mixture components with high resolution. Thus, it is commonly applied in the separation of coffee constituents such as the following: chlorogenic acid, trigonelline, caffeine, sugars, and amino acids [10, 21-24].

As sugars do not have conjugated $\pi$-bonds, they cannot be directly detected by UV-vis spectroscopy, requiring reactions of pre- or post-column derivatization $[25,26]$. Therefore, refractive index detection (RID) is widely used for sugars in food and beverages, where its concentration is not a limiting factor. Furthermore, it has a relatively low acquisition cost, and it is suitable for separation of components from simple mixtures due to its low sensitivity and selectivity detection

This is an open-access article distributed under the terms of the Creative Commons Attribution-NonCommercial 4.0 International License (https://creativecommons.org/licenses/by-nc/4.0/), which permits unrestricted use, distribution, and reproduction in any medium for non-commercial purposes, provided the original author and source are credited, a link to the CC License is provided, and changes - if any - are indicated. 
$[27,28]$. However, the use of organic solvents, commonly used in HPLC separation, is incompatible with refractive index detectors, requiring the use of polar solvents close to neutrality.

In this study, soluble sugars were extracted from green coffee beans with hot water using an orbital incubator shaker or a microwave. The experiments were carried out in a factorial design of $2^{3}$, varying the sample amount, time, and temperature of extraction. Additionally, we developed a quantification method for sucrose, glucose, and fructose by HPLC-RID using water as the mobile phase. Thus, we aimed to provide an optimal condition for sugar extraction from green coffee beans, which may be used in research institutions and food industries, along with a validated chromatographic method for carbohydrate separation and quantification.

\section{Experimental}

Plant Material. The sample was provided by the Agronomic Institute of Paraná (IAPAR), and consisted of a mixture of C. arabica (Iapar 59, Obatã, Catuaí, Mundo Novo, and Icatu), cultivated in northern Paraná, Brazil, containing less than 80 defects, as described by Brasil (2003) [29]. The green coffee beans were frozen in liquid nitrogen $\left(-196{ }^{\circ} \mathrm{C}\right)$ to avoid degradation of chemical constituents, and then, they were ground in a disk mill (PERTEN 3600). Subsequently, the samples were sieved in a 200 mesh, and stored in a freezer at $-18{ }^{\circ} \mathrm{C}$.

Reagents and Standards. The sugar standards used in the study were sucrose (Synth, Brazil), D(+)-glucose, and D(-)fructose (Merck, Darmstadt, Germany) with 98.90\%, 99.50\%, and $99.90 \%$ purity, respectively. The ultrapure water used in the solutions, in sugar extraction, and in the chromatographic system was purified by a Milli-Q system (Simplicity 185, Millipore, MA, USA).

Extraction of Sugars. The sugar extraction was conducted in an experiment arranged in a factorial design $2^{3}$ (Box, Hunter, \& Hunter), in triplicate at the central point. The factors and levels analyzed were the sample amount (300, 400 , and $500 \mathrm{mg}$ ), time (30, 60, and $90 \mathrm{~min})$, and temperature
(30, 45, and $\left.60{ }^{\circ} \mathrm{C}\right)$. The ground green coffee samples were transferred to flasks containing $20 \mathrm{~mL}$ of ultrapure water, and then subjected to extraction using an orbital incubator shaker or a microwave applying $800 \mathrm{~W}$ [30], with time and temperature programmed according to the factorial design. After extraction, the suspensions were centrifuged at $1048 \mathrm{~g}$ for $10 \mathrm{~min}$, and the supernatants were filtrated by a cellulose ester membrane with a pore size of $0.22 \mu \mathrm{m}$. Then, the samples were stored at $5{ }^{\circ} \mathrm{C}$ for further quantification of sugars. The flowchart (Figure 1) shows the steps taken from the sugar extraction to quantification.

Quantification of Sugars. Sugars were separated by HPLC (Shimadzu, Kyoto, Japan) using a cation exchange column, composed of $8 \%$ cross-linked divinylbenzene and $\mathrm{Pb}^{2+}$ ions (Aminex HPX-87P, $300 \mathrm{~mm} \times 7.8 \mathrm{~mm}, 9 \mu \mathrm{m}$, Bio-Rad, USA), placed in an oven at $80{ }^{\circ} \mathrm{C}$. Ultrapure water was used as the mobile phase at a flow rate of $0.8 \mathrm{~mL} / \mathrm{min}$. A manual injector Rheodyne ${ }^{\circledR} 7125$ containing a $20-\mu \mathrm{L}$ sampling loop was used to introduce the samples into the system. A RID$10 \mathrm{~A}$ refractive index detector (Shimadzu, Kyoto, Japan) was used for sugar detection and the integration of peaks, and area values were obtained using Class-VP software. Sugar identification was carried out according to retention times and addition of standards to the sample. Individual quantification of sugars was performed by external standardization using analytical curves, comprised of 6 concentrations of a mixture with glucose, sucrose, and fructose.

Chromatographic Method Validation. The method was validated following protocols of the AOAC and the International Union of Pure and Applied Chemistry (IUPAC) [31, 32], complying with the International Organization for Standardization (ISO) 11292 and 10504 standards, with adaptations in the sugar extraction and detection [33, 34].

Data Analysis. The means of sugar concentrations were compared using the independent-samples student's $t$-test, or Wilcoxon, in the case of residues not normally distributed. The planning of the experiments and the estimation of the effects of the extraction factors and its levels, along with the best extraction condition, were performed in the Statistica ${ }^{\circledR}$ software (significant at $\alpha=0.05$ ).

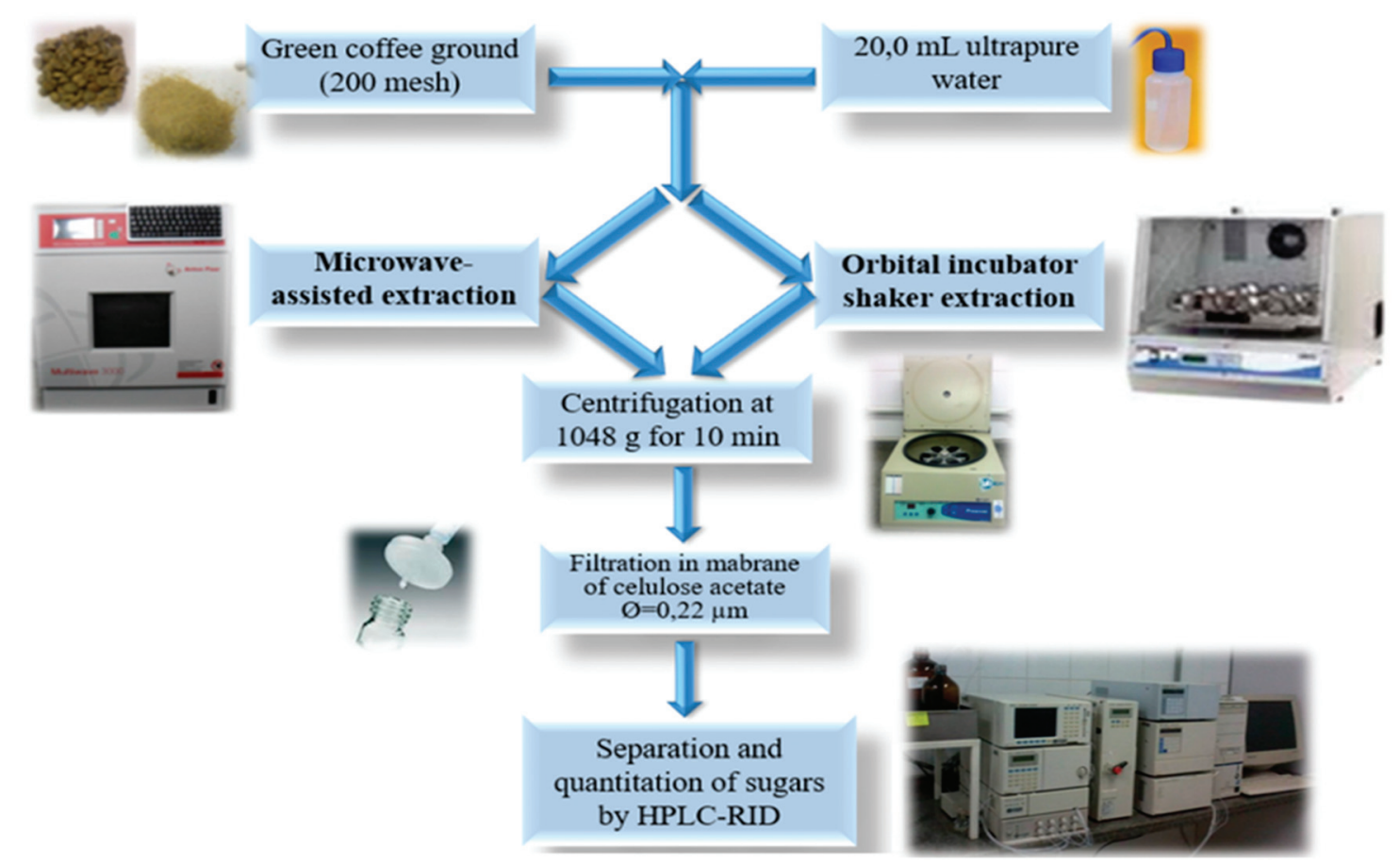

Figure 1. Flowchart showing the steps taken from the soluble sugar extraction to quantification 


\section{Results and Discussion}

Chromatographic Method Validation. Sensitivity (detection and quantification limits), precision, selectivity, recovery, and linearity were determined to validate the HPLCRID method for sugar quantification. The limit of detection (LOD) refers to the lowest concentration of an analyte in a sample that can be detected, but not necessarily quantified. However, the quantification limit (LOQ) is the lowest concentration of an analyte in a sample that can be determined with acceptable accuracy and precision [35]. The LOD of the proposed method was $0.020 \mathrm{~g} / \mathrm{L}$, and the LOQ was $0.0625 \mathrm{~g} /$ $\mathrm{L}$, for the 3 sugar types analyzed, using successive dilutions of the analytes to the lowest reliable signal of detection.

The repeatability (intra-day) and inter-day precision were estimated by 7 successive injections of each sugar standard in the HPLC-RID. The repeatability of the method showed $0.45 \%, 1.48 \%$, and $0.85 \%$ relative standard deviation for sucrose, glucose, and fructose, respectively. The inter-day precision, for 3 days of evaluation, presented a relative standard deviation of $0.67 \%$ for sucrose, $1.09 \%$ for glucose, and $2.60 \%$ for fructose.

Selectivity indicates the ability of the method to distinguish the analyte of interest from other components in the blend $[36,37]$. The chromatogram of the sucrose, glucose, and fructose separation is shown in Figure 2, indicating no interference from other peaks at the retention time of the analytes.

The recovery assays were performed by adding $1 \%(w / v)$ sugars to the filtered green coffee extract. The chromatographic method showed recovery values from 95.81 to $99.97 \%$ for sugars from both extraction methods, as indicated in Table 1. Acceptable recovery involves the concentration and the purpose of the analysis. According to AOAC (2002), the limit of the recovery value should vary from 92 to $105 \%$ for $1 \%(\mathrm{~m} / \mathrm{v})$ sugar, which indicates that the proposed method shows good sugar recovery and reliable accuracy.

Linearity is the ability of the method to obtain results directly proportional to the analyte concentration in a defined working range [32]. The adjusted models, linear correlation coefficient, and dynamic working range are presented in Table 2. The results of the 3 calibration curves that presented $R^{2}$ values above 0.999 for each sugar confirm the linearity of the method.

The validation parameters indicated that the HPLC-RID method, using water as the mobile phase, is reliable for the separation and quantification of sucrose, glucose, and fructose. Additionally, this method allows the separation of disaccharides such as sucrose, unlike the method using anion exchange
Table 1. Recovery rate $(\%)$ of $1 \%(\mathrm{~m} / \mathrm{v})$ soluble sugars in green coffee extracts using an orbital incubator shaker or microwave-assisted extraction

\begin{tabular}{lcc}
\hline Sugar & Orbital incubator shaker & Microwave-assisted extraction \\
\hline Sucrose & 97.33 & 99.97 \\
Glucose & 97.34 & 95.81 \\
Fructose & 99.19 & 97.76 \\
\hline
\end{tabular}

Table 2. Equations of calibration curves, linear coefficients, and linear dynamic work ranges for soluble sugars

\begin{tabular}{lccc}
\hline Sugar & Adjusted model & $\begin{array}{c}\text { Linear correlation } \\
\text { coefficient }(p<0.01)\end{array}$ & $\begin{array}{c}\text { Linear track work } \\
\text { dynamic }(\mathrm{g} / \mathrm{L})\end{array}$ \\
\hline Sucrose & $\begin{array}{c}y=1.60 \times 10^{6} \\
x+18,834\end{array}$ & 0.99938 & $0.0625-100.0$ \\
Glucose & $\begin{array}{c}y=1.44 \times 10^{6} \\
x+17,195\end{array}$ & 0.99971 & $0.0625-150.0$ \\
Fructose & $\begin{array}{r}y=1.96 \times 10^{6} \\
x+17,195\end{array}$ & 0.99955 & $0.0625-150.0$ \\
\hline
\end{tabular}

chromatography coupled with electrochemical detection by pulsed amperometry (HPLC-HPAE-PAD), proposed by ISO (1995) for soluble coffee.

Quantification of Sugars and Evaluation of the Extraction Conditions. The conditions, namely, $500 \mathrm{mg}$ of coffee, $90 \mathrm{~min}$, and $60{ }^{\circ} \mathrm{C}$, promoted the highest extraction yields of soluble sugars, for both incubator techniques (OIS and MAE) (Figure 3). Sucrose concentration ranged from 0.65 to $2.39 \mathrm{~g} / \mathrm{L}$ using an OIS and from 1.19 to $2.72 \mathrm{~g} / \mathrm{L}$ using MAE. For glucose and fructose, the lowest and highest concentrations extracted were 0.08 and $0.12 \mathrm{~g} / \mathrm{L}$, respectively, using both techniques. Although MAE showed the highest sucrose yields compared to OIS, the total sugar concentrations did not differ among the techniques, according to the student's $t$-test $(p<0.05)$. Higher concentrations of sucrose extracted from $C$. arabica using MAE were also observed in other studies [8, 12, 38, 39].

The optimal conditions for sugar extraction using the 2 incubation techniques evaluated, estimated by the Statistica ${ }^{\circledR}$ software, are presented in Table 3. Although the sugar concentrations were not significantly different between the techniques, the use of OIS is recommended due to its lower acquisition cost compared to a microwave, even though MAE has a higher potential for sucrose extraction from green coffee beans. Moreover, OIS is easily found in research laboratories and may be used for diverse activities such as microbiological tests.

In the study of Passos \& Coimbra (2013), extraction using a microwave resulted in lower yields of carbohydrates compared to the present study, ranging from 0.34 to $0.96 \mathrm{~g} / \mathrm{L}$ [40].

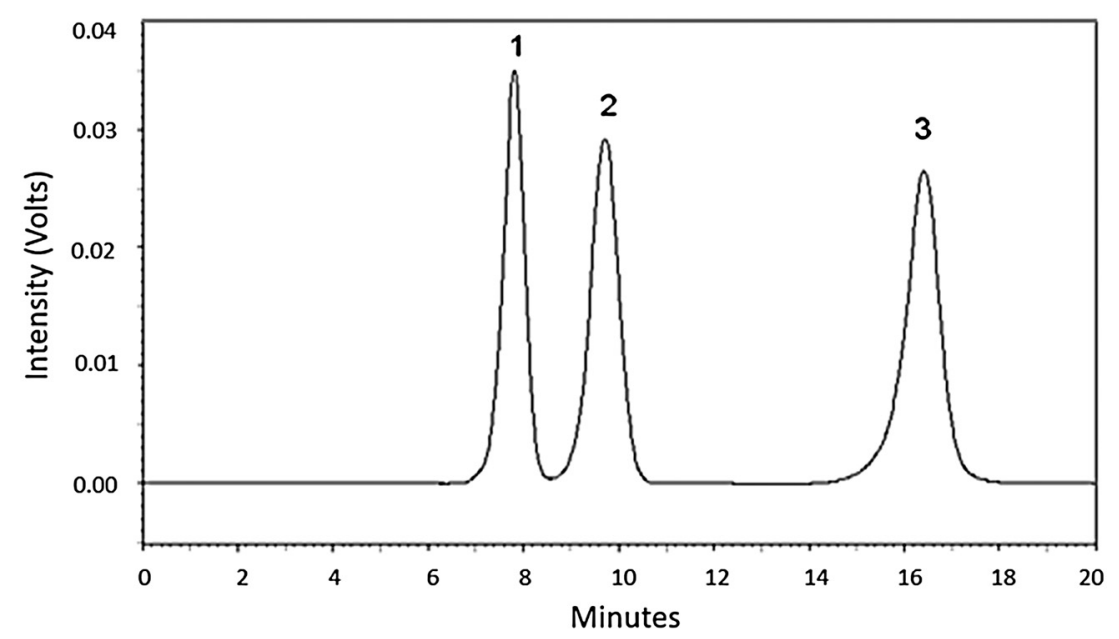

Figure 2. Chromatogram of sugars $10 \mathrm{~g} / \mathrm{L}$ and retention times: (1) sucrose (7.8 $\mathrm{min})$ (2) glucose (9.7 min), and (3) fructose (16.4 min) 

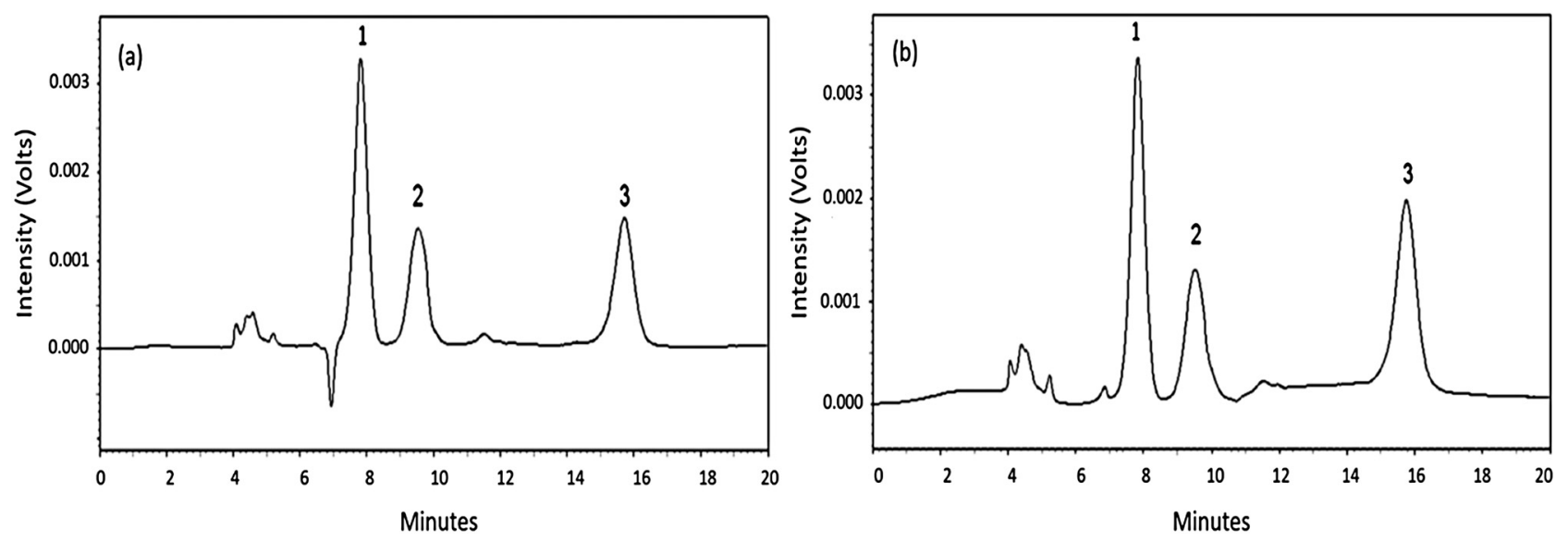

Figure 3. Chromatogram of (1) sucrose, (2) glucose, and (3) fructose from green coffee extracted by (a) an orbital incubator shaker and (b) microwave-assisted under the following conditions: sample amount $=500 \mathrm{mg}$, time $=90 \mathrm{~min}$, and temperature $=60{ }^{\circ} \mathrm{C}$

Table 3. The optimal conditions for soluble sugar extraction indicated by the desirability tool from software Statistica ${ }^{\circledR}$

\begin{tabular}{|c|c|c|c|c|}
\hline Factor & \multicolumn{2}{|c|}{ Orbital incubator shaker } & \multicolumn{2}{|c|}{ Microwave-assisted extraction } \\
\hline$\overline{\text { Amount (mg) }}$ & & & & \\
\hline Time $(\mathrm{min})$ & & & & \\
\hline Temperature $\left({ }^{\circ} \mathrm{C}\right)$ & & & & \\
\hline Sugar & {$[g / L]$} & $R^{2}$ & {$[g / L]$} & $R^{2}$ \\
\hline Sucrose & 2.16 & 0.800 & 2.36 & 0.996 \\
\hline Glucose & 0.10 & 0.900 & 0.10 & 0.894 \\
\hline Fructose & 0.20 & 0.870 & 0.07 & 0.951 \\
\hline
\end{tabular}

Values do not differ at $5 \%$ of probability by the independent-samples student's $t$-test.

Oosterveld, Harmsen, Voragen, \& Schols (2003) extracted sugars from green coffee with hot water at $170{ }^{\circ} \mathrm{C}$, which increased yields of galactomannans and galactans [10], unlike the present study that tested a maximum temperature of $60{ }^{\circ} \mathrm{C}$. The higher extraction temperature contributes to the solubilization of structural carbohydrates.

The concentration of soluble sugars in C. arabica may range from 6.25 to $9.00 \mathrm{~g}$ per $100 \mathrm{~g}$ for sucrose and from 0.1 to $1.0 \mathrm{~g}$ per $100 \mathrm{~g}$ for reducing sugars, such as glucose and fructose [5, 6, 16]. Knopp, Bytof, and Selma [41] found $7.07 \mathrm{~g} / 100 \mathrm{~g}, 0.27 \mathrm{~g} / 100 \mathrm{~g}$, and $0.39 \mathrm{~g} / 100 \mathrm{~g}$ for sucrose, glucose, and fructose, respectively, from green coffee beans $(C$. arabica L.), which were extracted using hot ethanol $(80 \% \mathrm{v} / \mathrm{v}$, $\left.80{ }^{\circ} \mathrm{C}\right)$ in an ultrasonic bath $\left(80^{\circ} \mathrm{C}, 10 \mathrm{~min}\right)$. In this research, the optimal condition for soluble sugar extraction using an OIS promoted 14.4, 0.40, and $0.80 \mathrm{~g}$ per $100 \mathrm{~g}$ for sucrose, glucose, and fructose, respectively. However, using MAE under the optimal conditions promoted 15.7, 0.40, and $0.28 \mathrm{~g}$ per $100 \mathrm{~g}$ for sucrose, glucose, and fructose, respectively. Comparison of the sugar concentrations revealed that OIS and MAE using hot water are as high as those in the hot ethanol $(80 \%)$, or even higher.

Thus, new low-cost alternatives for sugar extraction, such as the OIS and MAE using hot water, may contribute to the search for coffee cultivars with greater genetic potential regarding their characteristic. The balance between sugars, along with high sucrose concentrations, influences the caramelization process, contributing to the flavor of roasted grains and, consequently, the beverage quality.

\section{Conclusion}

The HPLC-RID method validated in this study was capable of separating and quantifying sucrose, glucose, and fructose from green coffee beans. In addition, we proposed an alternative and effective method of extracting soluble sugars compared to the ones recommended by the AOAC International. The use of orbital incubator shaker is preferably indicated as the incubator technique, using the optimal conditions as follows: $500 \mathrm{mg}$ ground green coffee, $90 \mathrm{~min}$, and $60{ }^{\circ} \mathrm{C}$. Finally, the development of new methods of extraction, separation, and quantification of green coffee sugars is highly relevant to laboratory research and food industry workflows.

\section{References}

1. Food and Agriculture Organization of the United Nations/FAOSTAT. Crops. http://www.fao.org/faostat/en/\#data/QC. Accessed Jan 2018.

2. Associação Brasileira da indústria de café/ABIC http://abic.com.br/ estatisticas/exportacoes/exportacao-brasileira-de-cafe-em-graos/. Accessed Jan 2018.

3. Fischer, M.; Reimann, S.; Trovato, V.; Redgwell, R. J. Carbohydr. Res. 2001, 330, 93-101.

4. Op, I. K. K. N.; Biology, P.; Io, T. U. C. T. Ann. Bot. 2008, 101, 31-38.

5. Farah, A. Coffee Constituents. In: Chu, Y. F. Coffee: Emerging Health

Effects and Disease Prevention, 1st ed.; Wiley-Blackwell: Oxford, 2012.

6. Duarte, G. S.; Pereira, A. A.; Farah, A. Food Chem. 2010, 118, 851-855.

7. Dessalegn, Y.; Labuschagne, M. T.; Osthoff, G.; Herselman, L. J. Sci. Food Agric. 2008, 88, 1726-1730.

8. Vaast, P.; Bertrand, B.; Perriot, J. J.; Guyot, B.; Genard, M. J. Sci. Food Agric. 2006, 86, 197-204.

9. Bradbury, A. G. W.; Halliday, D. J. J. Agric. Food Chem. 1990, 38 , 389-392.

10. Oosterveld, A.; Harmsen, J. S.; Voragen, A. G. J.; Schols, H. A. Carbohydr. Polym. 2003, 52, 285-296.

11. Baliza, D. P.; Santos, M. O.; Alves, J. D.; Guimarães, R. J.; Cunha, R. L. D. Coffee Sci. 2014, 9, 445-455.

12. Geromel, C.; Ferreira, L. P.; Davrieux, F; Guyot, B; Ribeyre, F; do Santos Scholz, M. B.; Androcioli Filho, A. Plant Physiol. Biochem. 2008, 46 , 569-579.

13. Somporn, C.; Kamtuo, A.; Theerakulpisut, P.; Siriamornpun, S. J. Sci. Food Agric. 2012, 92, 1956-1963.

14. Rogers, W. J.; Michaux, S.; Bastin, M.; Bucheli, P. Plant Sci. 1999 $149,115-123$

15. Oestreich-Janzen, S. Chemistry of Coffee. In: HAGE, D. S. Reference Module in Chemistry, Molecular Sciences and Chemical Engineering, Elsevier Inc., pp. 1-28.

16. Arya, M.; Rao, L. J. M. Crit. Rev. Food Sci. Nutr. 2007, 47, 51-67.

17. Redgwell, R.; Fischer, M. Braz. J. Plant Physiol. 2006, 18, 165-174.

18. Official methods of analysis of the association of official analytical chemists, 15th ed. AOAC, Washington, DC, 1990.

19. Poisson, L.; Schmalzried, F.; Davidek, T.; Blank, I.; Kerler, J. J. Agric. Food Chem. 2009, 57, 9923-9931.

20. Nunes, F. M.; Coimbra, M. A. J. Agric. Food Chem. 2002, 50, 7046-7052.

21. Geromel, C.; Ferreira, L. P.; Guerreiro, S. M. C.; Cavalari, A. A.; Pot, D.; Pereira, L. F. P.; Marraccini, P. J. Exp. Bot. 2006, 57, 3243-3258.

22. Murkovic, M.; Derler, K. J. Biochem. Biophys Methods 2006, 69, 25-32. 23. Mussatto, S. I.; Carneiro, L. M.; Silva, J. P. A.; Roberto, I. C.; Teixeira, J. A. Carbohydr. Polym. 2011, 83, 368-374.

24. Vignoli, J. A.; Bassoli, D. G.; Benassi, M. T. Food Chem. 2011, 124, $863-868$.

25. Pauli, E. D.; Cristiano, V.; Nixdorf, L. Quim. Nova 2011, 34, 689-694.

26. Casal, S.; Oliveira, M. B.; Ferreira, M. A. J. Liq. Chromatogr. Relat. Technol. 1998, 21, 3187-3195.

27. Caldas, B. S.; Constantino, L. V.; Silva, C. H. G. A.; Madeira, B. T.; Nixdorf, L. S. Sci. Chromatogr. 2015, 7, 53-63.

28. Femia, R. A.; Weinberger, R. J. Chromatogr. A 1987, 402, 127-134. 
29. Brasil, Instrução Normativa n. 8 , de 11 de junho de 2003, Aprova Regulamento técnico de identidade e de qualidade para a classificação do café beneficiado grão cru. http://www.sapc.embrapa.br/arquivos/consorcio/ legislacao/Instrucao Normativa n 8.pdf. Accessed Jan 2018.

30. Upadhyay, $\bar{R}$.; Ramalakshmi, K.; Jagan Mohan Rao, L. Food Chem. 2012, 130, 184-188.

31. Guidelines for single laboratory validation of chemical methods for dietary supplements and botanicals. https://www.aoac.org/aoac prod imis/ AOAC_Docs/StandardsDevelopment/SLV_Guidelines_Dietary_Supplements.pdf. Accessed Jan 2017

32. Thompson, M.; Ellison, S. L. R.; Wood, R. Pure Appl. Chem. 2002, 74, $835-855$.

33. ISO. ISO 11292: Instant coffee - Determination of free and total carbohydrate contents. Method using high performance anion-exchange chromatography, 1995.
34. ISO. ISO 10504: Starch derivatives - Determination of the composition of glucose syrups, fructose syrups and hydrogenated glucose syrups. Method using high-performance liquid chromatography, 2013.

35. Shrivastava, A.; Gupta, V. Chron. Young Sci. 2011, 2, 21.

36. Martínez-Miranda, M.; Taborda-Ocampo, G.; Rosero-moreano, M. J. Braz. Chem. Soc. 2015, 26, 797-803.

37. Felicio, A. L. S. M.; Monteiro, A. M.; Almeida, M. B.; Madeira, T. B.; Nixdorf, S. L.; Yabe, M. J. S. An. Acad. Bras. Cienc. 2016, 88, 1235-1241.

38. Silwar, R.; Lullmann, C. Café, Cacao, Thé. 1988, 32, 31-322.

39. dos Santos Scholz, M. B.; da Silva, J. V. N.; de Figueiredo, V. R. G.; Kitzberger, C. S. G. Coffee Sci. 2013, 8, 6-16.

40. Passos, C. P.; Coimbra, M. A. Carbohydr. Polym. 2013, 94, 626633.

41. Knopp, S.; Bytof, G.; Selma, D. Eur. Food Res. Technol. 2006, 223, 195-201. 